\title{
Phosphorus release from coastal sediments: Impacts of the oxidation-reduction potential and sulfide
}

\author{
Zhaoran Li ${ }^{\mathrm{a}}$, Yanqing Sheng ${ }^{\mathrm{a}, *}$, Jian Yang ${ }^{\mathrm{a}}$, Edward D. Burton ${ }^{\mathrm{b}}$ \\ ${ }^{a}$ Research Center for Coastal Environment Engineering Technology of Shandong Province, Yantai Institute of Coastal Zone Research, Chinese Academy of Sciences, Yantai 264003, China \\ b Southern Cross GeoScience, Southern Cross University, Lismore, New South Wales 2480, Australia
}

\section{A R T I C L E I N F O}

\section{Article history:}

Received 11 April 2016

Received in revised form 1 September 2016

Accepted 2 September 2016

Available online $\mathrm{xxxx}$

\section{Keywords:}

Oxidation-reduction potential

Phosphorus

Sulfur

Coastal river

Sediments

\begin{abstract}
A B S T R A C T
The release of phosphorus (P) from benthic sediments can affect the $\mathrm{P}$ content, nutrient status and quality of overlying waters in coastal ecosystem. This study was carried out to investigate the influence of oxidation-reduction potential (ORP) and sulfide on P release from sediments in the coastal estuary of the Yuniao River, China. The results showed that ferric iron-bound $\mathrm{P}$ was the main $\mathrm{P}$ burial phase in the sediments. The $\mathrm{P}$ concentration in overlying water increased with ORP decrease and sulfide increase, displaying a significant linear correlation with the ORP and sulfide concentration. The results indicate that decreased ORP may elevate the zero equilibrium phosphorus concentration, enhancing the capability of $P$ release. And increased sulfide may react or capture reactive iron in sediments, reducing the $P$ adsorption capacity and accelerating P release. Therefore, the control of ORP and sulfide production is important in the sink/source conversion of $\mathrm{P}$ in coastal sediments.
\end{abstract}

(c) 2016 Elsevier Ltd. All rights reserved.

\section{Introduction}

Phosphorus $(\mathrm{P})$ is an essential nutrient for biological productivity, and therefore plays an important role in oceans and continents. The total input of P into aquatic systems is determined by both external inputs as well as internal recycling from the benthic sediments to the water column (Pan et al., 2013; Kraal et al., 2015). Excessive input of P can lead to eutrophication, which adversely affects coastal zone ecosystems in many areas around the world (Yang et al., 2015). Phosphorus retention and release processes in estuarine and coastal sediments are also significant for the global $\mathrm{P}$ cycle because a great portion of $\mathrm{P}$ ( $25 \%$ dissolved $\mathrm{P})$ is trapped in such sediments and thus does not reach the open ocean (Ruttenberg, 1993; Paytan and McLaughlin, 2007).

Under some conditions, benthic sediment may act as an important $\mathrm{P}$ source for the overlying water (Sondergaard et al., 1999), and even create N-limited condition (Ferrera et al., 2016). P exchange processes between the sediment and overlying water are known to be affected by physico-chemical conditions and biological processes, which can also influence the existing forms of P (Qian et al., 2011; Pan et al., 2013). Anoxic marine sediments are generally thought to have diminished sedimentary P retention capacity (Ingall et al., 1993). Recent work has provided detailed insight into the relationship between reducing conditions and diminished sedimentary P sequestration (Kraal et al., 2015). Previous studies report that $\mathrm{P}$ flux between sediment and overlying

\footnotetext{
* Corresponding author.

E-mail address: yqsheng@yic.ac.cn (Y. Sheng).
}

water may be strongly influenced by physico-chemical conditions, such as temperature, dissolved oxygen (DO) and pH Smith et al., 2006; Lake et al., 2007; Berbel et al., 2015). In particular, oxidation-reduction potential (ORP) may be an especially crucial factor controlling the release of $P$ to the overlying water from sediments. In this regard, P-sediment adsorption experiments may be useful in examining the ORP-dependent ability of sediment to either remove or release P to the overlying water (Lyons et al., 1998; Pan et al., 2002).

The P cycle in coastal ecosystem can be strongly coupled to sediment iron (Fe) and sulfur (S) transformations (Kraal et al., 2015). Understanding the interaction between $\mathrm{Fe}, \mathrm{P}$ and $\mathrm{S}$ is key to predicting their biogeochemical fates and impact on water quality. In estuarine sediments rich in organic matter, oxygen is quickly depleted with microbial aerobic respiration below the sediment-water interface, thereby creating an anoxic environment. Under these conditions, both microbial iron reduction (Taillefert et al., 2000a) and sulfate reduction will occur (Burton et al., 2011). Iron reduction results in the dissolution of iron oxides to ferrous iron, whereas sulfate reduction results in the generation of sulfide. In the presence of sulfide, the $\mathrm{Fe}^{2+}$ ion can be quickly and effectively removed from pore waters by the formation of $\mathrm{FeS}$ and $\mathrm{FeS}_{2}$, which also removes the toxic sulfide in the sediment-water system (Taillefert et al., 2000b). The biogeochemical reactions of Fe and S also affect both availability of sedimentary $\mathrm{P}$ to aquatic organisms and mobility of P within the sediments (Rozan et al., 2002).

In light of the global increase in the areal extent of coastal marine systems that experience oxygen depletion and alterations in benthic $\mathrm{P}$ cycling in response to eutrophication, it is of considerable interest to clarify the ORP-dependent P release processes (Diaz and Rosenberg, 
2008; Middelburg and Levin, 2009; Qian et al., 2011). Therefore, the goals of this study were 1) to investigate the influence of ORP on P release from sediments in a polluted coastal estuary using a combination of $\mathrm{P}$ adsorption experiments and selective extractions across an experimentally-controlled range of ORP conditions; and 2) to investigate the influence of sulfide addition on P release from sediments.

\section{Methods and materials}

\subsection{Sampling and handling}

The Yuniao River originates from the Muping City (Yantai, China) urban area ( 0.4 million population), and carries about $60 \%$ of the municipal sewage of the city. The river is located in the northeastern Shandong province in northern China on the Bohai Strait and the southern coast of the Northern Yellow Sea $\left(37^{\circ} 23^{\prime} 35^{\prime \prime} \mathrm{N}, 121^{\circ} 33^{\prime}\right.$ $59^{\prime \prime} \mathrm{E}$; Fig. 1). The river is a typical seasonal river, with domestic and industrial wastewater discharge accounting for most of the river water during the dry season (Sun et al., 2016). The tide in the river estuary is a regular semidiurnal tide, and therefore the water quality is variable (Li et al., 2016). Sediment samples were collected from the Yuniaohe River estuary using a Van-Veen grab sampler, and were stored in zip-lock plastic bags on ice in an adiabatic box. Before analysis, the samples were freeze-dried and sieved (80 mesh). All reagents used were analytical grade or above, and deionized water (Milli-Q) was used to prepare the overlying water. Milli-Q water was deoxygenated by purging with high-purity $\mathrm{N}_{2}$ (>30 min).

\subsection{Measurements and methods}

Concentrations of $\mathrm{P}, \mathrm{Fe}$ (digestion prior to determination) and chemical oxygen demand $\left(\mathrm{COD}_{\mathrm{Cr}}\right.$, acid $\mathrm{COD}_{\mathrm{Mn}}$ and alkaline $\left.\mathrm{COD}_{\mathrm{Mn}}\right)$ were measured with the corresponding method specified in the standard methods by APHA (2005). In brief, this involved the dichromate titration method for $\mathrm{COD}_{\mathrm{Cr}}$, acid and alkaline permanganate titration method for acid $\mathrm{COD}_{\mathrm{Mn}}$ and alkaline $\mathrm{COD}_{\mathrm{Mn}}$ respectively. Dissolved oxygen (DO) and ORP in overlying water were measured using Unisense meters and electrodes. Five solid-phase fractions of P (loosely sorbed P, E\&L-P; ferric iron-bound P, Fe-P; authigenic carbonate fluorapatite + biogenic apatite $+\mathrm{CaCO}_{3}$-associated P, ACa-P; detrital apatite P, De-P; and organic P, Or-P) in the sediment samples were determined by a sequential extraction method (SEDEX) (Ruttenberg, 1992). The concentrations of total nitrogen (TN), total sulfur (TS) and total organic carbon (TOC) in sediments were measured by an elemental analyzer (Vario MACRO cube, Elmentar, Germany). The precision of the measurements was $\leq 0.5 \%$.

\subsection{ORP-dependent $P$ release experiments}

A group of experiments were set up to investigate the impact of the ORP on P release. In an anaerobic chamber, freeze-dried sediment was added to 6 beakers (named a, b, c, d, e, f) with anaerobic deionized water to achieve a sediment concentration of $10 \mathrm{~g} \mathrm{~L}^{-1}$ in each beaker. After allowing the sediment-water system to stabilize for $24 \mathrm{~h}$, the DO and ORP were then measured. At the same time, a $5 \mathrm{~mL}$ sample of the supernatant water was collected from each beaker without disturbing the sediment-water interface to measure the concentration of $P$. Then, different dosages of $\mathrm{NaBH}_{4}$ were added to achieve different ORP values in each beaker. $24 \mathrm{~h}$ later, DO, ORP and P were again measured.

\subsection{Adsorption isotherm experiments}

To determine the zero equilibrium phosphate concentration $\left(\mathrm{EPC}_{0}\right)$ for sediment samples under different ORP conditions, $0.20 \mathrm{~g}$ of freezedried sediment was placed in 48 polypropylene centrifuge tubes with $20 \mathrm{~mL}$ anaerobic deionized water. The 48 tubes were divided into 6 groups (A-F, with different ORP values), with each group containing 8 tubes. Each group was spiked with $\mathrm{KH}_{2} \mathrm{PO}_{4}$ to provide a range of initial phosphorus concentrations ( $\left.0,0.5,1.0,2.0,6.0,10.0,15.0,20.0 \mathrm{mg} \mathrm{L}^{-1}\right)$. The tubes were placed in a shaking bath $\left(150 \mathrm{rpm}, 25^{\circ} \mathrm{C}\right)$ for $24 \mathrm{~h}$. After $24 \mathrm{~h}$, each tube was centrifuged ( $3000 \mathrm{rpm})$, then aqueous $\mathrm{P}$ was measured after filtration to $<0.45-\mu \mathrm{m}$. The difference in $\mathrm{P}$ between the start and the end of the sorption experiment, along with the sediment dosage were used to calculate the amount of adsorbed P. Sorption curves were obtained by plotting the aqueous equilibrium concentration of $\mathrm{P}$ against the amount of adsorbed $\mathrm{P}$ per kg sediment.

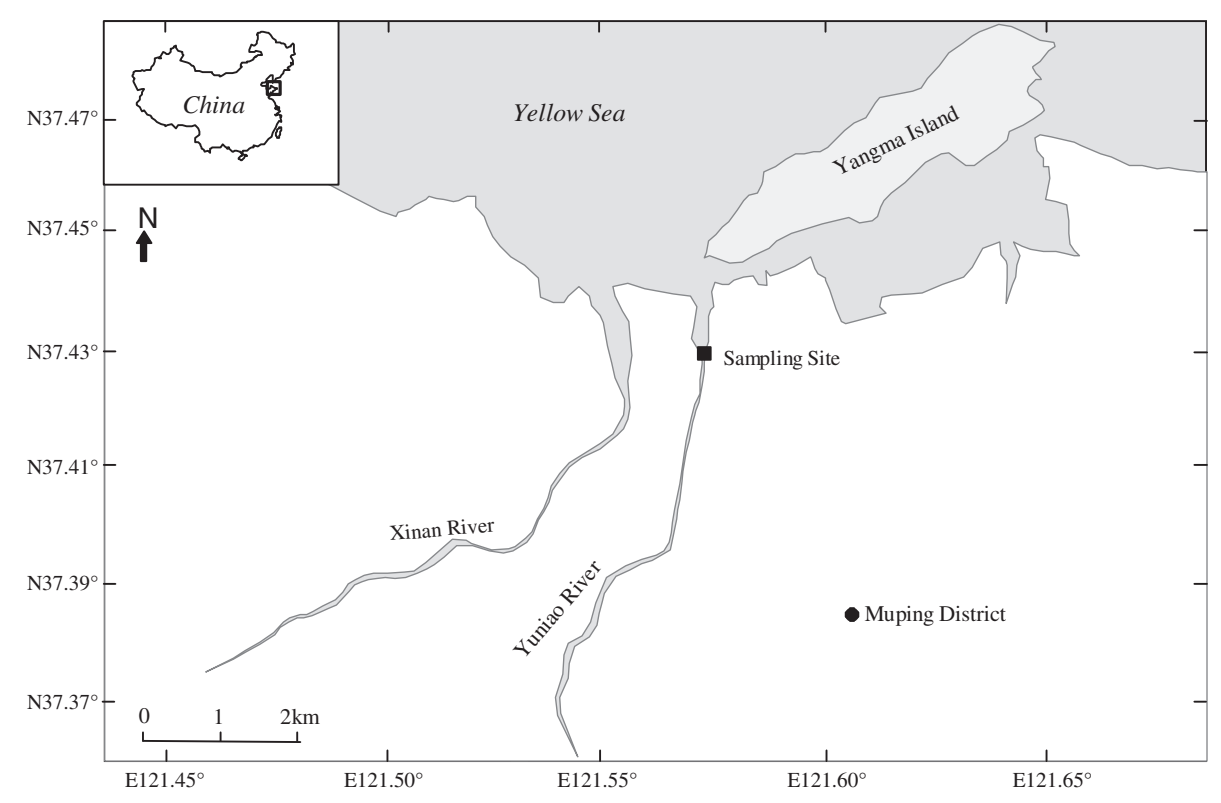

Fig. 1. Detailed location of the sampling site. 
Table 1

The average parameters of polluted river water.

\begin{tabular}{|c|c|c|c|c|c|c|}
\hline & \multirow[b]{2}{*}{$\begin{array}{l}\mathrm{COD}_{\mathrm{Cr}} \\
\left(\mathrm{mg} \mathrm{L}^{-1}\right)\end{array}$} & \multicolumn{2}{|c|}{$\mathrm{COD}_{\mathrm{Mn}}\left(\mathrm{mg} \mathrm{L}^{-1}\right)$} & \multirow[b]{2}{*}{$\begin{array}{l}\mathrm{DO}(\mathrm{mg} \\
\left.\mathrm{L}^{-1}\right)\end{array}$} & \multirow[b]{2}{*}{$\begin{array}{l}\text { Conductivity } \\
\left(\mathrm{ms} \mathrm{cm}^{-1}\right)\end{array}$} & \multirow[b]{2}{*}{$\begin{array}{l}\text { Salinity } \\
\text { (PSU) }\end{array}$} \\
\hline & & $\begin{array}{l}\text { Acid } \\
\text { method }\end{array}$ & $\begin{array}{l}\text { Alkaline } \\
\text { method }\end{array}$ & & & \\
\hline $\begin{array}{l}\text { Mean } \\
\text { value }\end{array}$ & 753.70 & 266.88 & 250.24 & 0.1 & 3.05 & 2.51 \\
\hline $\begin{array}{l}\text { Standard } \\
\text { (V) }\end{array}$ & 40 & 15 & / & 2 & I & I \\
\hline
\end{tabular}

\subsection{Sulfide addition on P release experiments}

A group of experiments were set up to investigate the impact of the sulfide addition on $P$ release. The general experiment design was same as the steps in Section 2.3; freeze-dried sediment was added to 6 beakers (named a, b, c, d, e, f) with anaerobic deionized water to achieve a sediment concentration of $10 \mathrm{~g} \mathrm{~L}^{-1}$ in each beaker. After allowing the sediment-water system to stabilize for $24 \mathrm{~h}$, a $\mathrm{Na}_{2} \mathrm{~S} \cdot 9 \mathrm{H}_{2} \mathrm{O}$ stock solution was added to 6 beakers to achieve a sulfide concentration of 0,5 , $10,15,20$ and $30 \mathrm{mg} \mathrm{L}^{-1}$ in each beaker, respectively. After $24 \mathrm{~h}$, the concentrations of sulfide, $\mathrm{Fe}^{2+}$ and $\mathrm{P}$ in supernatant water of each beaker were then measured.

\section{Results and discussion}

\subsection{Estuary pollution characteristics and in-situ P geochemistry}

In the Yuniao River, the average concentrations of $\mathrm{COD}_{\mathrm{Cr}}$ and acid $\mathrm{COD}_{\mathrm{Mn}}$ were much higher than the lowest surface water quality level (Chinese Standard, Level V, SEPA, 2002), indicating that the Yuniao River had been heavily polluted with regard to oxygen demand (Table 1).

The average concentrations of TOC, TN and TS in sediments were $7.67 \mathrm{wt} \%, 1.20 \mathrm{wt} \%$ and $1.30 \mathrm{wt} \%$, respectively, which are similar to the Dihe River in northern China (Sheng et al., 2013), but the TOC is higher than the lowest level of Marine Sediment Quality $\left(4 \times 10^{-6} \mathrm{wt} \%\right)$ (AQSIQ 2001). The results suggest that the sediments in the estuary are rich in organic matter because of long term pollution via sewage inputs. The sediment sample had a high concentration of total $\mathrm{Fe}$ (9361 $\mathrm{mg} \mathrm{kg}^{-1}$, Table 2) and a correspondingly high total P concentration (1897 $\mathrm{mg} \mathrm{kg}^{-1}$ ), much higher than the average background P concentration for all the bay sediments in Japan is $452 \mathrm{mg} \mathrm{kg}^{-1}$ (Fukue et al., 1999). Phosphorus in the surface sediments was predominantly present as Fe-P, with minor contributions from ACa-P, E\&L-P, and Or-P (Table 2). Generally, iron hydroxide and iron oxides have the strongest adsorption capacity for $\mathrm{P}$ among the various types of natural particles (Berner, 1973). Therefore, in Yuniao River estuary, the low oxygen and high organic matter conditions (Tables 1 and 2) may promote the formation of ACa-P and diminish the preservation of Fe-P. However, in sediment sample examined here, the concentration of Fe-P is much higher than ACa-P, which may be related to sediment's relatively high total Fe concentration. Under oxygen-depleted conditions when organic matter degradation is retarded, Or-P is generally the dominant source of $\mathrm{P}$ to the sediment surface and makes up a significant proportion of the sedimentary P reservoir (Ingall et al., 1993; Froelich et al., 1988; Follmi,

Table 2

The average concentrations of $\mathrm{P}, \mathrm{Fe}, \mathrm{C}, \mathrm{N}$ and $\mathrm{S}$ in the surface sediments (unit: $\mathrm{mg} \mathrm{kg}^{-1}$ ).

\begin{tabular}{lllllll}
\hline & E\&L-P & Fe-P & ACa-P & De-P & Or-P & Total P \\
\hline Mean value & 246.02 & 1092.29 & 285.34 & 95.64 & 178.20 & 1897.49 \\
& Fe $($ III $)$ & Total Fe & TOC (\%) & TN (\%) & TS (\%) \\
\hline Mean value & 6214.62 & 9361.97 & 7.67 & 1.20 & 1.3
\end{tabular}

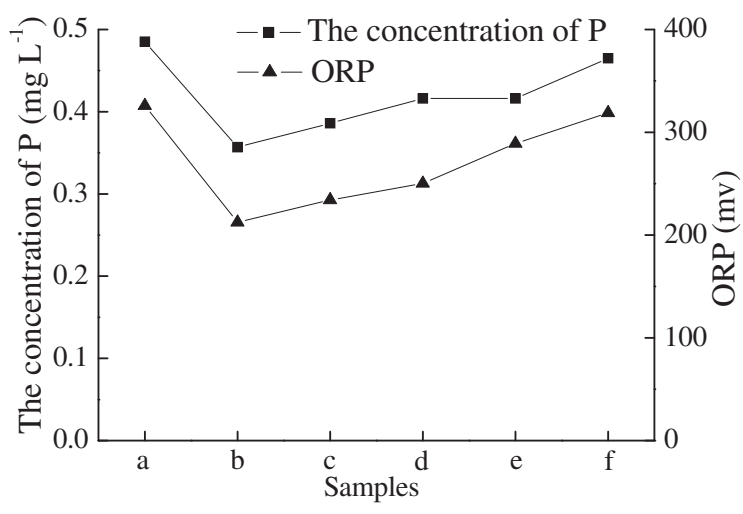

Fig. 2. The concentration of $P$ and ORP in different samples (a-f, with the same initial conditions) before $\mathrm{NaBH}_{4}$ addition.

1996; Jilbert et al., 2011). However, Or-P played a minor role in the sedimentary P reservoir in Yuniaohe River sediment examined here. This may be partly relating to the extraction methods used for Or-P. Or-P, measured by SEDEX, merely reflects the refractory organic $P$. In particular, degradable or soluble organic P may not be included because it would be released to the overlying water through pore water. Given that the refractory organic $P$ is relatively stable, a portion may be flushed from the sediment by tidal currents, allowing transport into the ocean. In addition, mineralization of organic $P$ at the sediment surface would release phosphate to the water column by turbulent mixing (Lee et al., 1977). Thus, Or-P is not the dominant source of $P$ to the sediment surface in this work.

\section{2. $P$ variability under different ORP conditions}

Prior to our experimental manipulation of the ORP the average concentration of $P$ in the overlying water was $0.42 \mathrm{mg} \mathrm{L}^{-1}$ with average ORP at $272 \mathrm{mv}$ (Fig. 2). In order to investigate the influence of ORP on $\mathrm{P}$ release from sediment, the trends of different $\mathrm{P}$ concentrations with ORP in overlying water are presented in Fig. 3. It can be seen from Fig. 3, the concentration of $P$ increases with the ORP decrease, and that the concentration of $\mathrm{P}$ and ORP has a significant linear correlation $(r-0.8934, P<0.05)$. These results clearly indicate that $\mathrm{P}$ release is strongly influenced by the variation of ORP.

Generally, reducing conditions may lead to diminished $\mathrm{Fe}$ (III) (oxyhydr)oxide concentrations. Under such conditions, it is expected that the Fe-P fraction could be released to the overlying water because of the reductive dissolution of Fe(III) (oxyhydr)oxide in sediment (House and Denison, 2000). At the same time, the inhibition of apatite

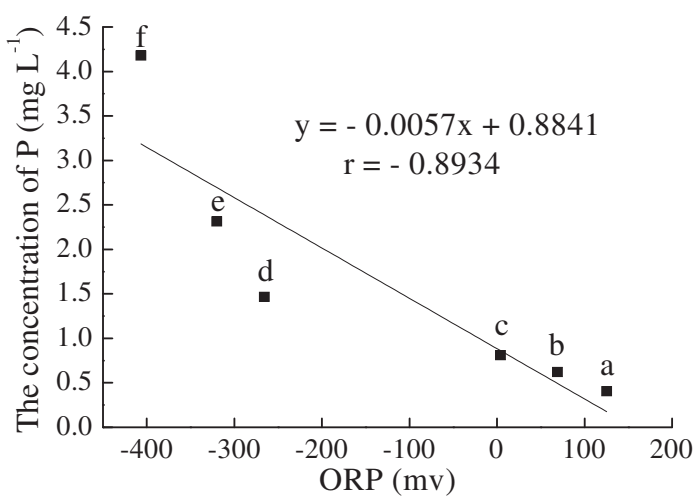

Fig. 3. Correlation between ORP and the concentration of $\mathrm{P}$ in the overlying water after different amount $\mathrm{NaBH}_{4}$ addition. 

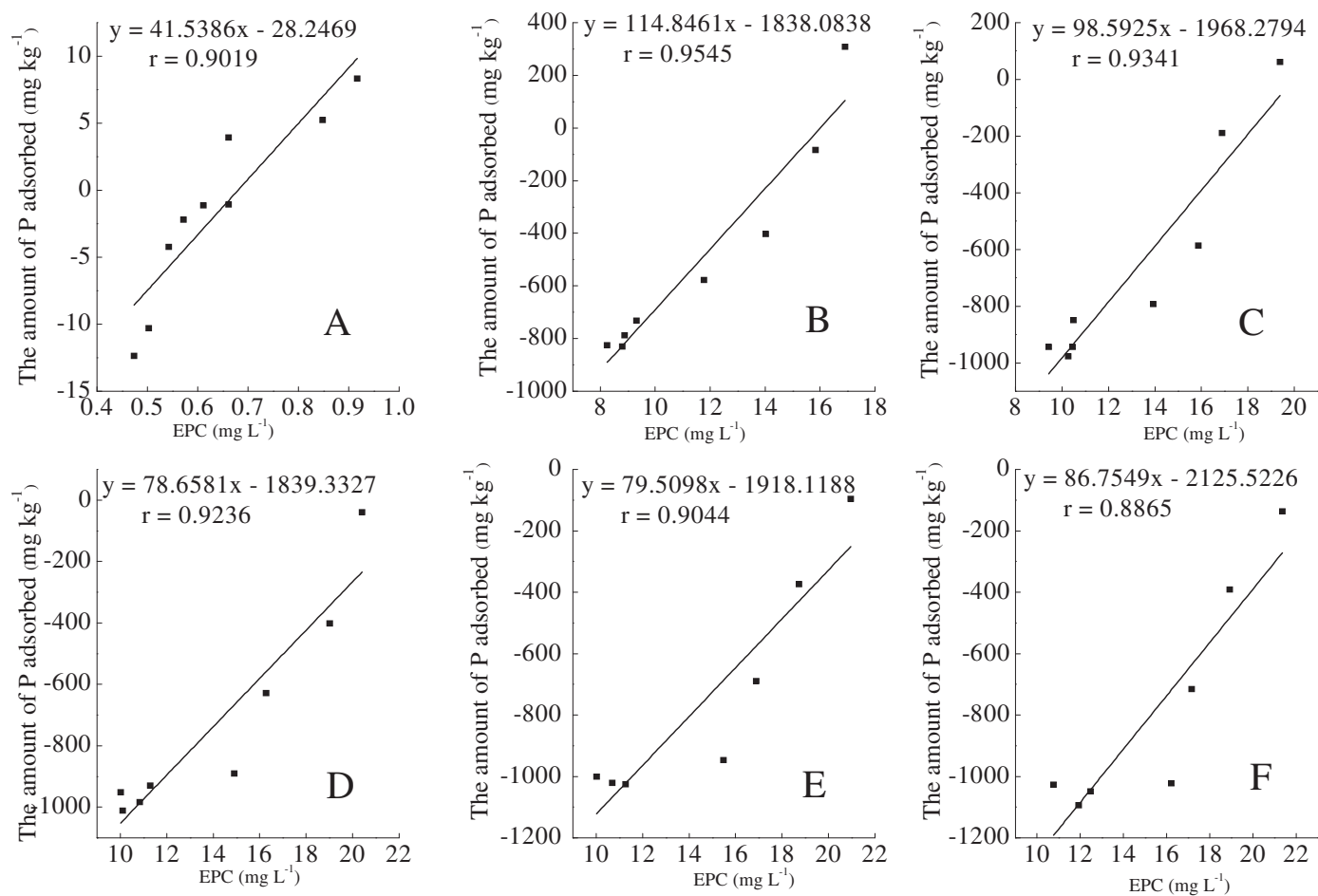

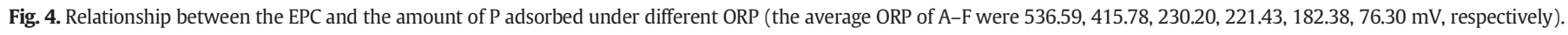

formation may result in low sorption capacity of reduced sediments and, therefore, the released P may accumulate in the water column (Kraal et al., 2015).

The concentration of $\mathrm{P}$ in the beaker $a$ (without $\mathrm{NaBH}_{4}$ addition) was comparable to the average $\mathrm{P}$ concentration before $\mathrm{NaBH}_{4}$ addition (Fig. 3 ). This means that there was negligible net adsorption or release of $P$ from sediment from 24 to $48 \mathrm{~h}$. However, after $48 \mathrm{~h}$, the P concentrations in $b-f$ beakers were much higher than the average $P$ concentration $\left(0.42 \mathrm{mg} \mathrm{L}^{-1}\right.$ ) before $\mathrm{NaBH}_{4}$ addition (Fig. 2). This indicates that the experimentally-altered ORP disrupted the original balance between $P$ release and $\mathrm{P}$ adsorption. Furthermore, this also hints that ORP may affect the value of $\mathrm{EPC}_{0}$, whereby the $\mathrm{EPC}_{0}$ increases with the ORP decrease.

\subsection{The effects of $\mathrm{ORP}$ on $\mathrm{EPC}_{0}$ and the distribution $\mathrm{P}$ fractions}

In order to investigate the P release mechanism from sediment, the relationship between the equilibrium $P$ concentration (EPC) and the amount of $\mathrm{P}$ adsorbed under different ORP (Fig. 4), correlation between ORP and $\mathrm{EPC}_{0}$ (Fig. 5) and the distribution of $\mathrm{P}$ fractions in the surface

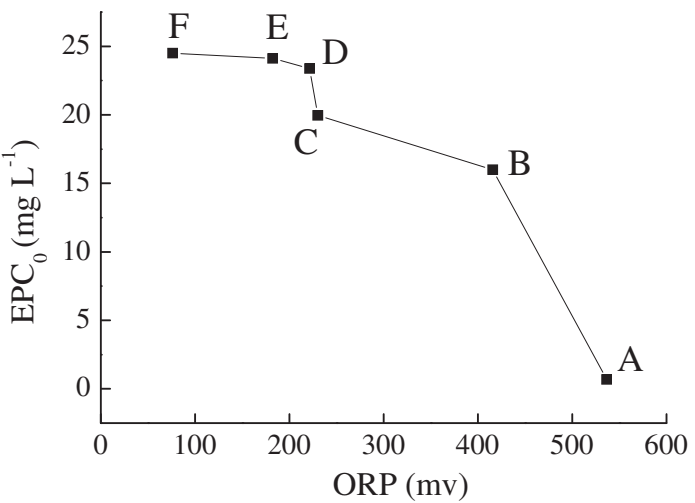

Fig. 5. Correlation between $\mathrm{ORP}$ and $\mathrm{EPC}_{0}$. sediments after $\mathrm{NaBH}_{4}$ addition (Fig. 6) were plotted. From Fig. 5, it can be seen that the $\mathrm{EPC}_{0}$ decreases significantly as the ORP increases. Generally, low $\mathrm{EPC}_{0}$ indicates a high affinity of sediments to sorb $\mathrm{P}$, and vice versa, the sediments with higher $\mathrm{EPC}_{0}$ have a higher potential to release P (Agudelo et al., 2011). After adding $\mathrm{NaBH}_{4}$, the decreased $\mathrm{ORP}$ may result in the $\mathrm{EPC}_{0}$ increase. This leads to the $\mathrm{EPC}_{0}$ being greater than the P concentration in the overlying water, thereby causing the sediment to act as a P source to the aqueous-phase (Kunishi et al., 1972). As a result, the concentration of $P$ in the overlying water increased significantly with the ORP decrease.

In Table 3, NAP represents native adsorbed $\mathrm{P}$ at the start of the experiment, $\mathrm{Q}$ is the amount of $\mathrm{P}$ adsorbed during the experiment, $\mathrm{K}$ is a sorption constant reflecting the sorption affinity of the sediment for $\mathrm{P}, \alpha$ is an empirical constant. $\mathrm{EPC}_{0}$ was calculated as the concentration of $\mathrm{P}$ at $\mathrm{Q}=0 \mathrm{mg} \mathrm{kg}^{-1}$ (Kraal et al., 2015).

Fig. 6 shows that, after $\mathrm{NaBH}_{4}$ addition, P was still predominantly present as Fe-P, with minor contributions from ACa-P, E\&L-P, and Or$P$. This suggests that the change of ORP may have caused insufficient bulk $\mathrm{P}$ release to cause a quantifiable change in the solid-phase $\mathrm{P}$

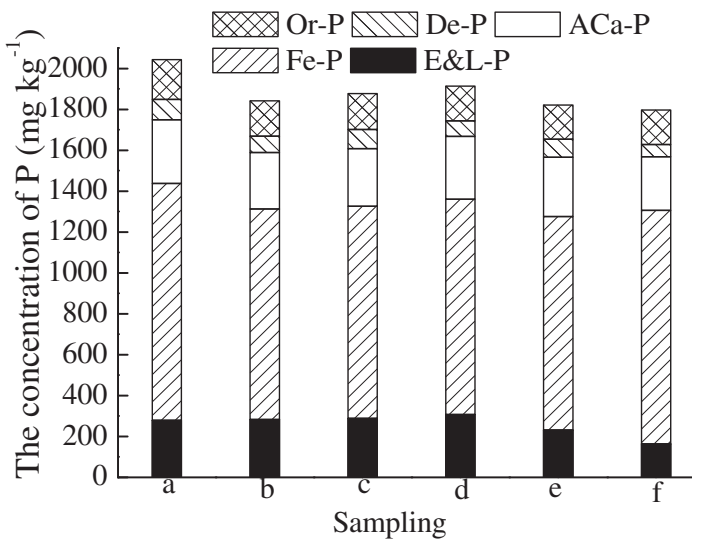

Fig. 6. The distribution of $\mathrm{P}$ fractions in the surface sediments after $\mathrm{NaBH}_{4}$ addition. 
Table 3

The P adsorption equilibrium concentrations and parameters of its adsorption isotherms by linear equation on sediments from the Yuniaohe River estuary.

\begin{tabular}{|c|c|c|c|c|c|c|}
\hline & Equation & $\mathrm{EPC}_{0}\left(\mathrm{mg} \mathrm{L}^{-1}\right)$ & $\mathrm{r}$ & $\operatorname{NAP}\left(\mathrm{mg} \mathrm{kg}^{-1}\right)$ & $\mathrm{K}\left(\mathrm{L} \mathrm{kg}^{-1}\right)$ & $\alpha$ \\
\hline A & $y=41.5386 x-28.2469$ & 0.680 & 0.9019 & 28.2469 & 41.5386 & 1 \\
\hline B & $\mathrm{y}=114.8461 \mathrm{x}-1838.0838$ & 16.005 & 0.9545 & 1838.0838 & 114.8461 & 1 \\
\hline C & $\mathrm{y}=98.5925 \mathrm{x}-1968.2794$ & 19.964 & 0.9341 & 1968.2794 & 98.5925 & 1 \\
\hline $\mathrm{D}$ & $y=78.6581 x-1839.3327$ & 23.384 & 0.9236 & 1839.3327 & 78.6581 & 1 \\
\hline $\mathrm{E}$ & $y=79.5098 x-1918.1188$ & 24.124 & 0.9044 & 1918.1188 & 79.5098 & 1 \\
\hline $\mathrm{F}$ & $y=86.7549 x-2125.5226$ & 24.500 & 0.8865 & 2125.5226 & 86.7549 & 1 \\
\hline
\end{tabular}

forms in sediments. Furthermore, the content of E\&L-P, Fe-P, ACa-P, De-P, and Or-P in sediments decreased with the ORP decrease, resulting in $\mathrm{P}$ increase in the overlying water.

Generally, Fe-P is relatively sensitive to alterations in ORP as well as $\mathrm{pH}$. Under reducing conditions, Fe oxides will undergo reductive dissolution, causing release of $\mathrm{Fe}(\mathrm{II})$ and a loss of P sorption sites (House and Denison, 2000). However, the results of this study show that there is no obvious relationship between ORP and Fe-P. This may be related to the high concentration of $\mathrm{Fe}(\mathrm{III})$ $\left(\sim 6200 \mathrm{mg} \mathrm{kg}^{-1}\right.$, Table 2$)$ in sediment. In addition, the interaction of $\mathrm{P}$ with sediments can occur via a reversible two-step sorption process: 1) adsorption/desorption on surfaces with fast kinetics (minutes-hours); 2) solid-state diffusion of adsorbed phosphate from the surface into the interior of particles with slow kinetics (days-months) (Froelich, 1988). Reactive iron oxide minerals have a high capacity for absorbing phosphate in the second step, possibly resulting in similar concentrations of Fe-P during the ORP changing process.

\subsection{The effects of sulfide addition on P release}

In order to investigate the influence of sulfide addition on $\mathrm{P}$ release from sediment, the relationship between $P$ concentrations and sulfide addition and the variations of ORP and $\mathrm{Fe}^{2+}$ concentration with sulfide addition in overlying water are plotted in Fig. 7. The $24 \mathrm{~h}$ equilibrated conditions reached without added sulfide were average concentrations of $\mathrm{P}$ and $\mathrm{Fe}^{2+}$ equaling 0.66 and $0.38 \mathrm{mg} \mathrm{L}^{-1}$, respectively (Fig. 6, left). It can be seen from Fig. 7 (left) that the concentration of P increased with sulfide, and that the concentration of $\mathrm{P}$ and sulfide therefore have a significant linear correlation ( $\mathrm{r} 0.9916, P<0.001$ ). This clearly indicate that the addition (or in-situ generation) of sulfide enhances $P$ release from sediments. At the same time, the concentration of $\mathrm{Fe}^{2+}$ increases with the ORP decrease (Fig. 7, right). Furthermore, a significant linear correlation also exists between $\mathrm{P}$ concentrations and $\mathrm{Fe}^{2+}$ concentrations in overlying water.

The results in these tests support the hypothesis that low ORP enhances P release from sediment. In this work, when the sulfide dosage increased, ORP would be decreased thereby driving the observed $\mathrm{P}$ release along with the release of $\mathrm{Fe}^{2+}$ via reductive dissolution of $\mathrm{Fe}$ (III) oxides. During this process, increased sulfide may react or capture reactive iron (with different forms) in sediments as Fe sulfide phases, reducing the P adsorption capacity and enhancing the $P$ release.

\section{Conclusions}

Fe-P is the main P burial phase in coastal sediments of the Yuniao River estuary, China. The $\mathrm{P}$ concentration in overlying water increased with ORP decrease and a significant linear correlation was evident between ORP and the concentration of $\mathrm{P}$. This result indicates that decreased ORP may elevate the value of $\mathrm{EPC}_{0}$, enhancing the capability of $P$ release from sediments. The results also indicate that increased sulfide may react with reactive iron (with different forms) in sediments, reducing the $\mathrm{P}$ adsorption capacity and accelerating P release. Therefore, the control of ORP and sulfide production is important in the sink/source conversion of $P$ in coastal sediments.

\section{Acknowledgements}

This work was carried out with financial supported by the National Natural Science Foundation of China (Grant No.: 41373100). Additional supports were provided by Science and Technology Program for Public Wellbeing of Shandong Province (Grant No.: 2013kjhm060308) and CAS Key Technology Talent Program.
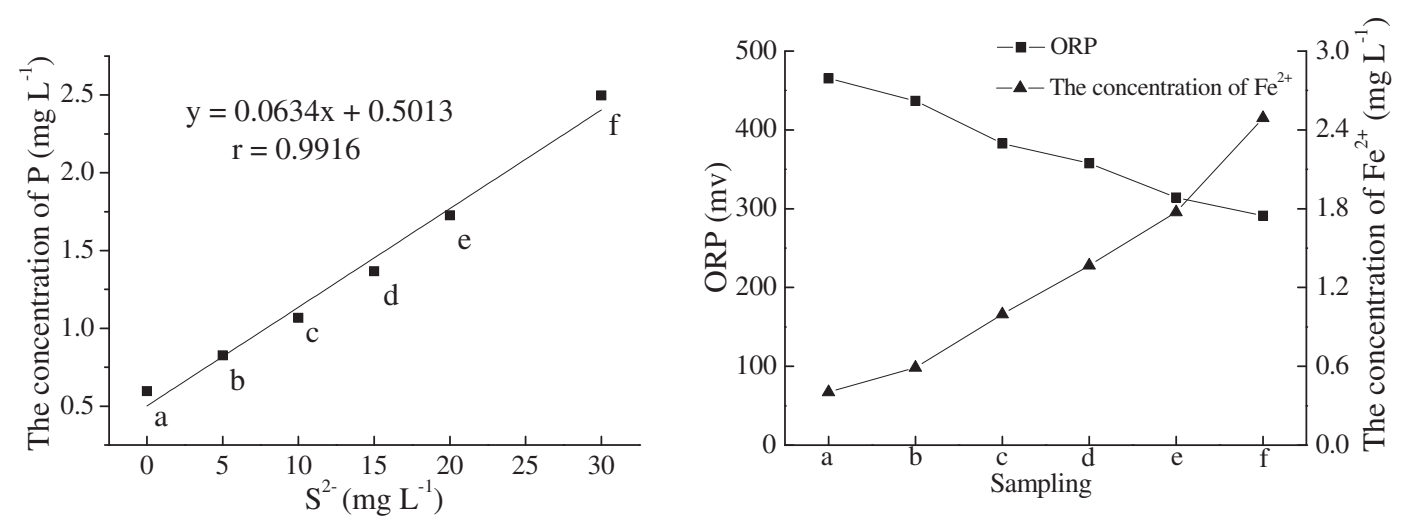

Fig. 7. The relationship between $\mathrm{P}$ and sulfide concentrations (left) and variations of ORP and $\mathrm{Fe}^{2+}$ after sulfide addition (right). 


\section{References}

Agudelo, S.C., Nelson, N.O., Barnes, P.L., Keane, T.D., Pierzynski, G.M., 2011. Phosphorus adsorption and desorption potential of stream sediments and field soils in agricultural watersheds. J. Environ. Qual. 40 (1), 144-152.

APHA, 2005. Standard Methods for the Examination of Water and Wastewater. American Public Health Association-American Water Works Association-Water Environment Federation.

AQSIQ, 2001. Marine Sediment Quality (GB 18668-2002). Standards Press of China, Beijing, China, pp. 1-6 (In Chinese).

Berbel, G.B.B., Favaro, D.I.T., Braga, E.S., 2015. Impact of harbour, industry and sewage on the phosphorus geochemistry of a subtropical estuary in Brazil. Mar. Pollut. Bull. 93, 44-52.

Berner, R.A., 1973. Phosphate removal from sea water by adsorption on volcanogenic ferric oxides. Earth Planet. Sci. Lett. 18, 77-86.

Burton, E.D., Bush, R.T., Johnston, S.G., Sullivan, L.A., Keene, A.F., 2011. Sulfur biogeochemical cycling and novel Fe-S mineralization pathways in a tidally re-flooded wetland. Geochim. Cosmochim. Acta 75, 3434-3451.

Diaz, R.J., Rosenberg, R., 2008. Spreading dead zones and consequences for marine ecosystems. Science 321 (5891), 926-929.

Ferrera, C.M., Watanabe, A., Miyajima, T., Diego-McGlone, M.L.S., Morimoto, N., Umezawa, Y., Herrera, E., Tsuchiya, T., Yoshikai, M., Nadaoka, K., 2016. Phosphorus as a driver of nitrogen limitation and sustained eutrophic conditions in Bolinao and Anda, Philippines, a mariculture-i impacted tropical coastal area. Mar. Pollut. Bull. http://dx.doi. org/10.1016/j.marpolbul.2016.02.025.

Follmi, K.B., 1996. The phosphorus cycle, phosphogenesis and marine phosphate-rich deposits. Earth Sci. Rev. 40 (1-2), 55-124.

Froelich, P.N., 1988. Kinetic control of dissolved phosphate in natural rivers and estuaries: a primer on the phosphate buffer mechanism1. Limnol. Oceanogr. 33 (4), 649-668.

Froelich, P.N., Arthur, M.A., Burnett, W.C., Deakin, M., Hensley, V., Jahnke, R., Kaul, L., Kim, K.H., Roe, K., Soutar, A., Vathakanon, C., 1988. Early diagenesis of organic-matter in Peru continental-margin sediments-phosphorite precipitation. Mar. Geol. 80 (3-4), 309-343.

Fukue, M., Nakamura, T., Kato, Y., Yamasaki, S., 1999. Degree of pollution for marine sediments. Eng. Geol. 53, 131-137.

House, W.A., Denison, F.H., 2000. Factors influencing the measurement of equilibrium phosphate concentrations in river sediments. Water Res. 34 (4), 1187-1200.

Ingall, E.D., Bustin, R.M., Vancappellen, P., 1993. Influence of water column anoxia on the burial and preservation of carbon and phosphorus in marine shales. Geochim. Cosmochim. Acta 57 (2), 303-316.

Jilbert, T., Slomp, C.P., Gustafsson, B.G., Boer, W., 2011. Beyond the Fe-P-redox connection: preferential regeneration of phosphorus from organic matter as a key control on Baltic Sea nutrient cycles. Biogeosciences 8 (6), 1699-1720.

Kraal, P., Burton, E.D., Rose, A.L., Kocar, B.D., Lockhart, R.S., Grice, K., Bush, R.T., Tan, E., Webb, S.M., 2015. Sedimentary iron-phosphorus cycling under contrasting redox conditions in an eutrophic estuary. Chem. Geol. 392, 19-31.

Kunishi, H.M., Taylor, A.W., Heald, W.R., Gburek, W.J., Weaver, R.N., 1972. Phosphate movement from an agricultural watershed during two rainfall periods. J. Agric. Food Chem. 20 (4), 900-905.

Lake, B.A., Coolidge, K.M., Norton, S.A., Amirbahman, A., 2007. Factors contributing to the internal loading of phosphorus from anoxic sediments in six Maine, USA, lakes. Sci. Total Environ. 373 (2-3), 534-541.
Lee, G.F., Sonzogni, W.C., Spear, R.D., 1977. Significance of oxic vs anoxic conditions for Lake Mendota sediment phosphorus release. In: Golterman, H.L. (Ed.), Interactions Between Sediment and Fresh Water. Dr. W. Junk Publishers, Hague, pp. 294-306.

Li, Z., Sheng, Y., Shi, W., Sun, Q., Mortimer, R.J.G., 2016. Influence of salinity on COD measurements in coastal water management. Desalin. Water Treat. 57 (39), $18338-18345$.

Lyons, J.B., Gorres, J.H., Amador, J.A., 1998. Spatial and temporal variability of phosphorus retention in a riparian forest soil. J. Environ. Qual. 27 (4), 895-903.

Middelburg, J.J., Levin, L.A., 2009. Coastal hypoxia and sediment biogeochemistry. Biogeosciences 6 (7), 1273-1293.

Pan, G., Krom, M.D., Herut, B., 2002. Adsorption-desorption of phosphate on airborne dust and riverborne particulates in East Mediterranean seawater. Environ. Sci. Technol. 36 (16), 3519-3524.

Pan, G., Krom, M.D., Zhang, M.Y., Zhang, X.W., Wang, L.J., Dai, L.C., Sheng, Y.Q., Mortimer R.J.G., 2013. Impact of suspended inorganic particles on phosphorus cycling in the Yellow River (China). Environ. Sci. Technol. 47 (17), 9685-9692.

Paytan, A., McLaughlin, K., 2007. The oceanic phosphorus cycle. Chem. Rev. 107 (2), 563-576.

Qian, Y., Liang, X., Chen, Y., Lou, L., Cui, X., Tang, J., Li, P., Cao, R., 2011. Significance of biological effects on phosphorus transformation processes at the water-sediment interface under different environmental conditions. Ecol. Eng. 37 (6), 816-825.

Rozan, T.F., Taillefert, M., Trouwborst, R.E., Glazer, B.T., Ma, S., Herszage, J., Valdes, L.M. Price, K.S., Luther III, G.W., 2002. Iron-sulfur-phosphorus cycling in the sediments of a shallow coastal bay: implications for sediment nutrient release and benthic macroalgal blooms. Limnol. Oceanogr. 47 (5), 1346-1354.

Ruttenberg, K.C., 1992. Development of a sequential extraction method for different forms of phosphorus in marine sediments. Limnol. Oceanogr. 37 (7), 1460-1482.

Ruttenberg, K.C., 1993. Reassessment of the oceanic residence time of phosphorus. Chem. Geol. 107 (3-4), 405-409.

SEPA, 2002. Environmental Quality Standards for Surface Water (GB 3838-2002). China Environmental Sciences Press, Beijing, China (in Chinese).

Sheng, Y., Qu, Y., Ding, C., Sun, Q., Mortimer, R.J.G., 2013. A combined application of different engineering and biological techniques to remediate a heavily polluted river. Ecol. Eng. 57, 1-7.

Smith, D.R., Warnemuende, E.A., Haggard, B.E., Huang, C., 2006. Changes in sedimentwater column phosphorus interactions following sediment disturbance. Ecol. Eng. 27 (1), 71-78

Sondergaard, M., Jensen, J.P., Jeppesen, E., 1999. Internal phosphorus loading in shallow Danish lakes. Hydrobiologia 408, 145-152.

Sun, Q., Sheng, Y., Yang, J., Di Bonito, M., Mortimer, R.J.G., 2016. Dynamic characteristics of sulfur, iron and phosphorus in coastal polluted sediments, north China. Environ. Pollut. http://dx.doi.org/10.1016/j.envpol.2016.06.019.

Taillefert, M., Bono, A.B. Luther, G.W., 2000a. Reactivity of freshly formed Fe(III) in synthetic solutions and (pore)waters: voltammetric evidence of an aging process. Environ. Sci. Technol. 34, 2169-2177.

Taillefert, M., Bono, A.B., Luther, G.W., 2000b. Reactivity of freshly formed Fe(III) in synthetic solutions and (pore)waters: voltammetric evidence of an aging process. Environ. Sci. Technol. 34, 2169-2177.

Yang, B., Cao, L., Liu, S., Zhang, G., 2015. Biogeochemistry of bulk organic matter and biogenic elements in surface sediments of the Yangtze River Estuary and adjacent sea. Mar. Pollut. Bull. 96, 471-484. 